\title{
Editorial for EAIT issue 3, 2019
}

\section{Arthur Tatnall ${ }^{1}$}

Published online: 4 April 2019

(C) Springer Science+Business Media, LLC, part of Springer Nature 2019

Education and Information Technologies (EAIT) is the official journal of the IFIP Technical Committee on Education (TC3) and covers the complex relationships between information and communication technologies and education, from the micro of specific applications or instances of use in classrooms to macro concerns of national policies and major projects; from classes of 5 year olds to adults in tertiary institutions; from teachers and administrators, to researchers and designers; from institutions to open, distance and lifelong learning. The journal's breadth of coverage allows EAIT to examine fundamental issues at all levels, discuss specific instances and cases, draw inference and probe theory. This journal is embedded in the research and practice of professionals.

In addition to the regular articles, also in this issue is a list of all the reviewers who completed an EAIT review in 2018. Completing a review for a journal article is a significant task requiring considerable time and effort and each review makes a very important contribution to the journal. Springer, the Associate Editors and I thank you all for your effort and dedication.

To begin this issue is an article: "Measurement of e-services quality: an empirical study of University of Bahrain" from Bahrain by Hayat Ali, University of Bahrain. The author indicates that ICT has significantly revolutionised the educational sector with an increasing number of universities making use of websites. For students, eservice quality has become a vital concern. With its pervasiveness in education the described research aimed at measuring e-services quality and its impact on student esatisfaction at University of Bahrain. The results showed that all dimensions of eservices quality have an impact on student's e-satisfaction.

To follow: "RemedialTutor: A blended learning platform for weak students and study its efficiency in social science learning of middle school students in India" is by Sujan Kumar from Birla Institute of Technology Mesra, India. Blended learning, which is one of the leading trends in education, combines computer-assisted learning with traditional classroom learning. While literature shows that blended learning often helps

Arthur Tatnall

Arthur.Tatnall@vu.edu.au

1 Victoria University, Melbourne, Australia 
most students, little of the existing learning platforms focuses on the problems of weak students. This paper presents RemedialTutor, which assists weaker students in effective preparation for an examination. It is provided to students as a supplement to traditional classroom activities and resources.

"A fuzzy classification approach for learning style prediction based on web mining technique in e-learning environments" comes next. The authors are: Ouafae El Aissaoui (Sidi Mohamed Ben Abdellah Univesity, Morocco), Yasser El Alami El Madani (Mohammed V University, Morocco), Lahcen Oughdir (Sidi Mohamed Ben Abdellah Univesity, Fez, Morocco) and Youssouf El Allioui (Hassan First University, Morocco). Adaptive E-learning platforms provide personalised learning process relying mainly on learning styles, and the traditional approach to find these depends on asking learners to self-evaluate their own attitudes and behaviours through surveys and questionnaires. This approach, however, presents several weaknesses. This paper proposes a generic approach for detecting learning styles automatically, according to a given learning styles model. Their results showed that this outperformed traditional approaches, providing promising results.

The next article comes from Hamadah Alsadoon and Thamer Alhussain (Saudi Electronic University, Riyadh, Saudi Arabia) and looks at: "Faculty at Saudi Electronic University attitudes toward using augmented reality in education". This examines the possibility of implementing Augmented Reality (AR) applications in higher education at Saudi Electronic University. The researchers looked at which academics at the university were familiar with these applications, what perceptions they held toward using them in education and what barriers they believed may hinder implementing this technology. They found that even though the faculty were at an accepted level of familiarity with this technology, they did not use it in their classes due to barriers such as the lack of technical support.

"Deciphering the attributes of student retention in massive open online courses using data mining techniques" was contributed by Shivangi Gupta and A. Sai Sabitha (Amity University Campus, India). Over the last few years, Massive Open Online Courses (MOOC) has evolved to engage millions of learners. Their study explores the attributes of student retention in e- learning. It proposes a rationale of significant attributes using classification algorithms (Decision Trees) in order to improve course design and delivery for different MOOC providers and learners.

Priyadarshini Dey and Somprakash Bandyopadhyay from Indian Institute of Management Calcutta, India next offer: "Blended learning to improve quality of primary education among underprivileged school children in India". Access to quality primary education is a major concern in India, and issues of teacher absenteeism, poor accountability of teachers, ineffective teaching and learning materials and inadequate teaching procedures are the prevailing causes for poor educational quality in lower tier schools. Studies have revealed that Internet-enabled, Web 2.0 based blended learning environments can stimulate student engagement, motivation, and learning. This paper presents an Internet-enabled blended-learning platform which combines traditional models of classroom interactions with synchronous e-learning with digital audiovisual contents, facilitated by expert online teachers. 
"Indonesia deaf and blind communication system (IDBC-system)" comes from Indonesia and is by Sunardi Tukimin, Dini Handayani, Zaenal Alimin and Permanarian Somad. Their research was motivated by the difficulty of interaction between deaf students and blind people in the context of friendship and buying and selling. These people cannot communicate well by means of existing communication. Communication between the visually impaired and deaf is a problem as deaf children are visual persons, while the blind child is an auditory person. The article describes the use of a modified Morse code system. Their results showed that communication between blind and deaf people through modified Morse code can aid interpersonal communication and interaction.

Nur Siyam of The British University in Dubai, United Arab Emirates next writes on "Factors impacting special education teachers' acceptance and actual use of technology". The described study uses the Technology Acceptance Model (TAM) to explore the factors that impact special education teachers' acceptance and actual use of technology. The study involved special education teachers in a private school in the UAE. They were asked questions relating to: Perceived Usefulness, Perceived Ease of Use, Attitudes Towards Usage, Behavioural Intention to Use, Access to Technology, Job Relevance, Self-Efficacy, Time and Actual Usage. Preliminary findings indicate that special education teachers have positive attitudes towards the use of technology. Self-efficacy, time and access to technology were found to significantly impact actual use of technology.

Building a virtual laboratory for teaching and learning is a highly complex process and this article focuses on the production and implementation issues that were found in the comparison of two different virtual laboratory projects and discusses which design considerations can be drawn from these observations. "Design considerations for virtual laboratories: A comparative study of two virtual laboratories for learning about gas solubility and colour appearance" describes research by: Beata Stahre Wästberg and Thommy Eriksson (Chalmers University of Technology and University of Gothenburg, Sweden), Göran Karlsson (Halmstad University, Sweden), Maria Sunnerstam and Michael Axelsson (University of Gothenburg, Sweden) and Monica Billger (Chalmers University of Technology, Sweden). In their research two web-based virtual laboratories: the Gas Laboratory and the Virtual Colour Laboratory were developed independently of each other within two different content areas. Through a comparison of production and outcome, similar problems relating to design, development and implementation were observed and five design challenges for developing virtual laboratories were identified.

“The impact of social networking sites on students' social wellbeing and academic performance" relates that social networking, as an educational tool for online courses, has significantly contributed in promoting students' motivation for learning. Sarminah Samad (Princess Nourah Bint Abdulrahman University, Saudi Arabia), Mehrbakhsh Nilashi and Othman Ibrahim (Universiti Teknologi Malaysia) investigated the impact of social networking sites on students' academic performance. Their survey results revealed that there is a positive relationship between social presence, students' social wellbeing and their academic performance.

The ability to categorise concepts is an essential capability for human thinking and action. In "Student strategies for categorizing IT-related terms", Torsten Brinda, Stephan Napierala and David Tobinski (University of Duisburg-Essen, Germany) and 
Ira Diethelm (University of Oldenburg, Germany) investigate this subject. They note that, on the one hand the investigation of such abilities is the purview of psychology but on the other hand, subject-specific educational research is also of interest, as a number of research works in the field of science education show. For computer science education, however, no corresponding studies are currently available. An empirical study with German students from primary to higher education presented the students with twenty three information technology-related terms with the task of assigning these to self-defined categories (and then giving their categories individual names). They found that the younger participants used less abstract names for their categories, and observed that some participants had difficulty categorising some terms (such as robot and 3D).

Talal Alasmari (University of Jeddah, Saudi Arabia) and Ke Zhang (Wayne State University, USA) then present: "Mobile learning technology acceptance in Saudi Arabian higher education: an extended framework and a mixed-method study" that reports a two-phase study with an extended framework on mobile learning technology acceptance, and a mixed-method research investigating college students use and embracement of mobile learning technology acceptance in Saudi Arabia, using the Unified Theory of Acceptance and Use of Technology (UTAUT). Their study found that Learning Expectancy (LE), Effort Expectancy (EE), Social Influence (SI) and characteristics of mobile learning were significant predictors of students' intentions to use mobile learning technologies, regardless of the moderating effects of gender, age, and eLearning experience.

"A new integrated model to explore factors that influence adoption of mobile learning in higher education: An empirical investigation" by Faisal Aburub (University of Petra, Jordan) and Ibrahim Alnawas (Qatar University) describes research aimed to test the combined effect of the key components of the Technology Acceptance Model (TAM) and those of the Usage and Gratification Approach $(\mathrm{U} \& \mathrm{G})$ on intention to adopt mobile learning in higher education. Their findings revealed that perceived ease of use and cognitive gratification had the highest impact on intention to adopt mobile learning, perceived usefulness and hedonic gratification had the lowest effect, and personal integrative gratification had no effect.

While various researchers have conducted work supporting the validity of selfdetermination theory (SDT) in conventional learning settings, few attempts have been made to explore its application in the online learning context. "Reexamining the impact of self-determination theory on learning outcomes in the online learning environment" by Hui-Ching Kayla Hsu (New York University, USA) and Cong Vivi Wang (Purdue University, USA) attempts to redress this. An earlier study had concluded that the SDT-based model was unable to predict the learning outcomes in online programs, but after analysing this model the researchers identified possible measurement issues and aimed to further examine the SDT-based model after modifications. Their results indicated that the satisfaction of basic psychological needs enhanced self-regulated motivation which was associated with higher perceived knowledge transfer and increased achievement of course objectives in online courses, and provides empirical evidence for the application of the SDT-based model in the online learning environment. 
The last article in this issue is: "Development of mathematical connection skills in a dynamic learning environment". Y1lmaz Zengin (Dicle University, Turkey) describes a study to examine the effect of GeoGebra software on pre-service teachers' mathematical connection skills. A mathematical connection self-efficacy scale and an openended questionnaire regarding mathematical connection skills were used as data collection tools. Based on the results it was determined that GeoGebra software could be used as an important tool for the development of mathematical connection skills.

Papers in this issue of EAIT come from researchers in the following countries: Bahrain, India, Morocco, Saudi Arabia, Indonesia, United Arab Emirates, Sweden, Malaysia, Germany, USA and Turkey.

\section{Arthur Tatnall}

Editor-in-Chief

Publisher's note Springer Nature remains neutral with regard to jurisdictional claims in published maps and institutional affiliations. 